\title{
Modest Decrements in Plasma Glucose Concentration Cause Early Impairment in Cognitive Function and Later Activation of Glucose Counterregulation in the Absence of Hypoglycemic Symptoms in Normal Man
}

\author{
Pierpaolo De Feo, Virgilio Gallai,“ Giovanni Mazzotta," Giuseppe Crispino, Elisabetta Torlone, Gabriele Perriello, \\ Mariarosa M. Ventura, Fausto Santeusanio, Paolo Brunetti, and Geremia B. Bolli \\ Istituto di Patologia Medica; and *Clinica Neurologica, University of Perugia, 06100 Perugia, Italy
}

\section{Abstract}

To establish the glycemic threshold for onset of neuroglycopenia (impaired cognitive function, measured by the latency of the $P 300$ wave), activation of hormonal counterregulation and hypoglycemic symptoms, 12 normal subjects were studied either under conditions of insulin-induced, glucose-controlled plasma glucose decrements, or during maintenance of euglycemia. A decrement in plasma glucose concentration from $88 \pm 3$ to $80 \pm 1 \mathrm{mg} / \mathrm{dl}$ for $150 \mathrm{~min}$ did not result in changes in the latency of the $P 300$ wave nor in an activation of counterregulatory hormonal response. In contrast, a greater decrement in plasma glucose concentration from $87 \pm 3$ to $72 \pm 1 \mathrm{mg} / \mathrm{dl}$ for 120 min caused an increase in the latency of the $P 300$ wave (from $301 \pm 12$ to $348 \pm 20 \mathrm{~ms}, P<0.01$ ), a subsequent increase in all counterregulatory hormones but no hypoglycemic symptoms. Finally, when plasma glucose concentration was decreased in a stepwise manner from $88 \pm 2$ to $50 \pm 1 \mathrm{mg} / \mathrm{dl}$ within $75 \mathrm{~min}$, the increase in the latency of the $P 300$ wave was correlated with the corresponding plasma glucose concentration $(r=-0.76, P<0.001)$. The glycemic threshold for hypoglycemic symptoms was $49 \pm 2 \mathrm{mg} / \mathrm{dl}$.

Thus, in normal man the glycemic threshold for neuroglycopenia $(72 \pm 1 \mathrm{mg} / \mathrm{dl})$ is greater than currently thought; the hormonal counterregulation follows the onset of neuroglycopenia; the hypoglycemic symptoms are a late indicator of advanced neuroglycopenia.

\section{Introduction}

Although theoretically the brain can oxidize substrates other than glucose, under normal conditions alternative substrates are either excluded by the blood-brain barrier or circulate at concentrations too low to be taken up in substantial quantities (1). Thus, glucose is the obligate fuel for the brain, and more than 90 percent of the energy needed for brain function derives from oxidation of glucose (2). Since the brain virtually cannot store or synthetize glucose, a constant supply of glucose from the circulation to the central nervous system is essential for normal brain function and whole body survival (1). Indeed,

Presented in part at the 47th Annual Meeting of the American Diabetes Association, 7-9 June 1987 in Indianapolis, IN.

Address reprint requests to Dr. Bolli, Istituto Patologia Medica, Universita di Perugia, Via E. dal Pozzo, 06100 Perugia, Italy.

Received for publication 8 September 1987 and in revised form 28 December 1987.

J. Clin. Invest.

(C) The American Society for Clinical Investigation, Inc. 0021-9738/88/08/0436/09 \$2.00

Volume 82, August 1988, 436-444 several studies in man have shown that brain function becomes impaired when plasma glucose concentration decreases $\sim 30-50 \mathrm{mg} / \mathrm{dl}$ below normal fasting values, as demonstrated by the abnormalities of neuropsychological tests (3-5), visual reaction time $(6)$, and electroencephalogram $(7,8)$. Since the abnormalities in brain function were not detected in these studies until plasma glucose concentration had reached a nadir of $\sim 55 \mathrm{mg} / \mathrm{dl}$, it is presently accepted that brain function becomes impaired in man only when plasma glucose concentration falls below $55 \mathrm{mg} / \mathrm{dl}$, whereas less severe plasma glucose decrements are generally considered harmless $(1,5)$. However, because the potentially deleterious effects of modest decrements in plasma glucose concentration on brain function have never been carefully examined, it cannot be excluded that the glycemic threshold for the onset of neuroglycopenia and brain dysfunction is actually greater than what is currently appreciated.

The present series of studies were undertaken to test the hypothesis that, first, brain function is sensitive to minor decreases in arterial plasma glucose concentration in man and, second, to establish the relationship between the decrease in plasma glucose concentration and the impairment in brain function. For this purpose, brain function was evaluated in normal subjects by means of auditory event-related potentials (a sensitive and specific test for cognitive function in man) during minor decreases in plasma glucose concentration. In addition, the responses of plasma counterregulatory hormones and substrates were determined, and the symptoms of hypoglycemia recorded.

\section{Methods}

Informed written consent was obtained from 12 normal volunteers (six males, six females) aged $27 \pm 1$ yr (mean \pm SEM), who were within $10 \%$ of their ideal body weight $(99 \pm 2 \%$, Metropolitan Life Insurance Co. Tables, 1959) and had no family history of diabetes mellitus. For at least three days before the study all subjects consumed a weight maintenance diet containing at least $250 \mathrm{~g}$ carbohydrate. All subjects were admitted to the metabolic unit between 8 and 8:30 a.m. after fasting overnight $(10-11 \mathrm{~h})$; they were placed at bed rest and maintained in the supine position throughout experiments. To obtain arterializedvenous blood samples, a hand vein was cannulated in retrograde fashion with a 19-gauge butterfly needle and maintained at $70^{\circ} \mathrm{C}$ in a thermoregulated plastic box (9). An antecubital vein of the contralateral arm was cannulated with a 18-gauge catheter and was used for insulin and glucose infusions.

An initial series of studies were designed to evaluate the threshold of the arterialized-venous plasma glucose concentration at which cerebral function becomes impaired and hormonal counterregulation is activated (study A). Three sets of experiments were performed in a single blind in six subjects (three male, three female) on three different occasions in random order, a week apart. In all studies insulin was infused intravenously at the rate of $20 \mathrm{mU} / \mathrm{m}^{2} \cdot \min$ for $180 \mathrm{~min}$. On 
one occasion plasma glucose concentration was maintained at the fasting value by means of the euglycemic clamp technique (10), as previously described (11). In the two other occasions, the glucose infusion rate was decreased to maintain the plasma glucose concentration $\sim 8 \mathrm{mg} / \mathrm{dl}$ on one occasion and $15 \mathrm{mg} / \mathrm{dl}$ on the other occasion below the fasting values for $150 \mathrm{~min}$.

An additional series of studies were designed to assess the relationship between decrements in arterialized-venous plasma glucose concentration and cognitive function, and the glycemic threshold at which hypoglycemic symptoms appear (study B). Two sets of experiments were performed in the remaining six subjects on two different occasions, in random order, a week apart. Insulin was infused at the rate of $40 \mathrm{mU} / \mathrm{m}^{2} \cdot \min$ for $75 \mathrm{~min}$. On one occasion euglycemia was maintained by means of the glucose clamp technique, on the other occasion plasma glucose concentration was allowed to decrease to a hypoglycemic plateau and subsequently to increase and return to normal values. The glucose infusion rate was varied to achieve the following steps of plasma glucose concentration after starting the insulin infusion: 70 $\mathrm{mg} / \mathrm{dl}$ between 20 and $25 \mathrm{~min}, 60 \mathrm{mg} / \mathrm{dl}$ between 35 and $40 \mathrm{~min}, 50$ $\mathrm{mg} / \mathrm{dl} \mathrm{between} 45$ and $75 \mathrm{~min}, 85 \mathrm{mg} / \mathrm{dl}$ between 105 and $135 \mathrm{~min}$.

In all the studies insulin (Actrapid MC, U-40; Novo Research Institute, Copenhagen, Denmark) diluted to $0.3 \mathrm{U} / \mathrm{ml}$ in $0.9 \% \mathrm{NaCl}$ containing $0.5 \%$ human albumin (Immuno S.p.A., Pisa, Italy) was infused intravenously using a pump (Harvard Apparatus Co., Inc., The Ealing Corp., South Natick, MA). Glucose ( $20 \%$ solution) was infused using a separate Harvard pump at variable rate. Arterialized-venous blood samples were collected at $2.5-15$-min intervals for immediate plasma glucose determination at bedside (glucose analyzer, Beckman Instruments, Inc., Fullerton, California) and for measurement of plasma insulin (12), glucagon (13), epinephrine (14), norepinephrine (14), cortisol (15), growth hormone (16), free fatty acids (FFA) $)^{1}(17)$, and 3-beta-hydroxybutyrate (B-OH-B) (18) by previously described methods. Cognitive function was evaluated every 10-30 min by measuring the latency of the $\mathrm{P} 300$ wave, which is the most prominent component of auditory event related potentials (19). Silver disk electrodes were fixed to the scalp in the positions $\mathrm{Fz}, \mathrm{Cz}$, and $\mathrm{Pz}(10-20$ EEG International System) with collodion and referred to linked mastoids. An additional electrode was placed lateral to the left eye to monitor blinks and other electro-oculographic artifacts. For each determination of the latency of P300 wave, 200 tone bursts (intensity 80 $\mathrm{db})$ were given binaurally through earphones at a rate of one every second; $78-82 \%$ of the tones had a frequency of $1,000 \mathrm{~Hz}$, and $18-22 \%$ had a frequency of $2,000 \mathrm{~Hz}$. The sequence of the frequent $(1,000 \mathrm{~Hz})$ and rare $(2,000 \mathrm{~Hz})$ tones was varied at random. The subjects were instructed to mentally count the number of the rare but not the frequent tones, and then asked to report the number of rare tones counted at the end of each run. The event-related potentials averaged $750 \mathrm{~ms}$ and consisted of a 150 -ms period before the stimulus onset and a 600-ms period after the stimulus appearance. The peak latency of the P300 wave was obtair.ed from the potentials evoked by the rare tones by using the points of intersection of "best-fit" slope lines on either side of the component peak $(20,21)$. All latency measures were derived from the $\mathrm{Cz}$ wave form. In our laboratory, the coefficient of variation (c.v.) of the determination of latency of P300 wave determined in 30 normal volunteers ( 17 male, 13 female; $28 \pm 0.3 \mathrm{yr}$ ) studied in the fasting state between 9 and 10 a.m. on three different occasions at $2-5$-d intervals was $7.2 \pm 0.6 \%$. The investigation on the $P 300$ wave was performed by means of a special apparatus for cognitive evoked potentials (Amplaid MK 7; Amplaid Inc., Rolling Meadows, IL).

In all the studies the subjects were unaware of the plasma glucose concentration and were asked to score at 15 -min intervals from 0 (none) to 5 (severe) the following symptoms: hunger, difficulty in thinking, faintness, dizziness, tingling, blurred vision, sweating, palpitations, anxiety, irritability and tremors. Henceforth, the first six

1. Abbreviations used in this paper: B-OH-B, 3-beta-hydroxybutyrate; FFA, free fatty acids. symptoms will be referred to as "neuroglycopenic" and the remaining five as "adrenergic." The symptom score was calculated both as the mean of the eleven symptoms and separately for the neuroglytopenic and adrenergic symptoms.

Data in text and figures are given as mean \pm SEM. The statistical significance was evaluated using the analysis of variance corrected for repeated measures (22). The dependent variables were compared during the hypoglycemic and euglycemic clamps to allow variability in the measurements with time under euglycemic conditions to be factored into the results. The threshold for onset of neuroglycopenia, activation of counterregulation and hypoglycemic symptoms was assumed at the plasma glucose concentration at which the parameter examined (mean \pm SEM) was significantly increased as compared to the control study (euglycemic clamp).

\section{Results}

\section{Study A}

Effects of minor decrements in plasma glucose concentration on brain function, hormonal counterregulation and symptoms of hypoglycemia. In all these studies plasma insulin concentration increased to a steady state value of $\sim 50 \mu \mathrm{U} / \mathrm{ml}$, with no differences between the studies in which plasma glucose was either maintained at baseline values, or allowed to decrease (Figs. 1 and 2; Tables I and II).

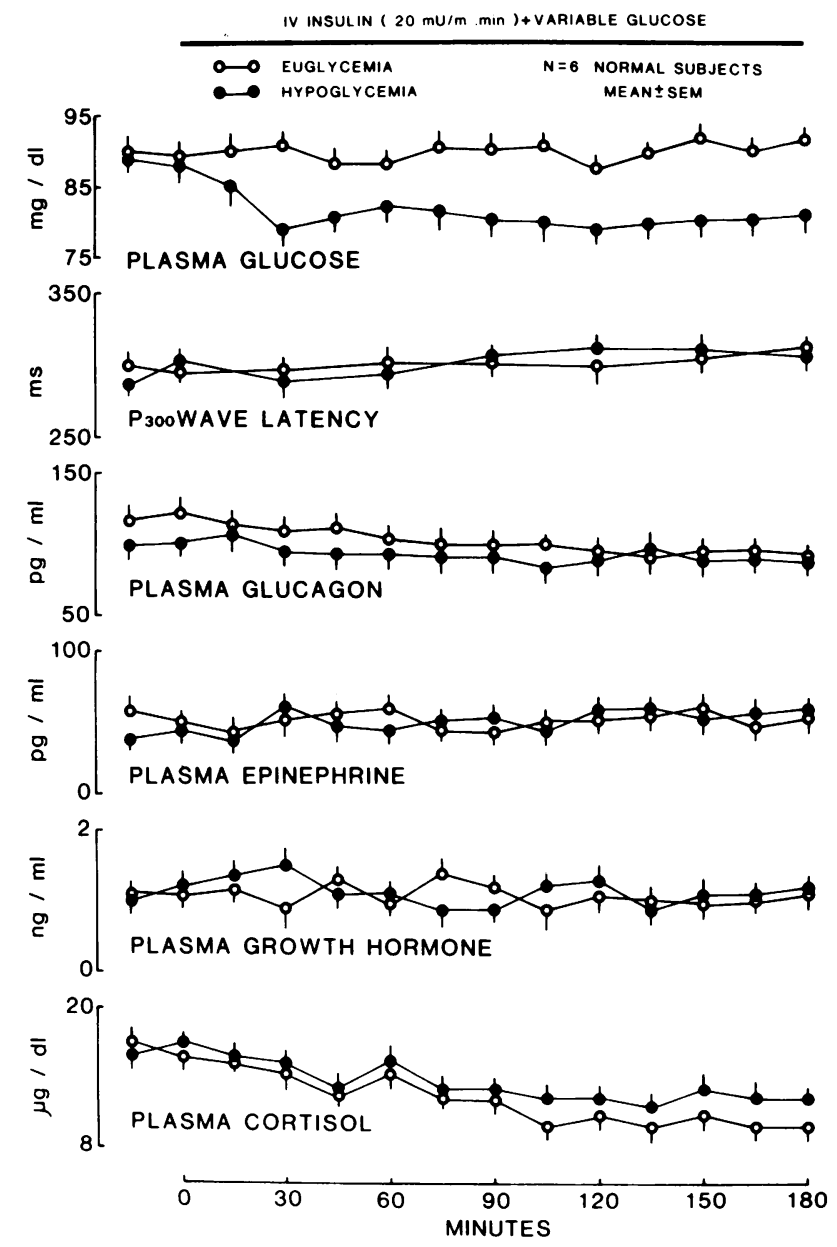

Figure 1. Cognitive function (latency of $\mathrm{P} 300$ wave), and plasma counterregulatory hormones in response to insulin-induced plasma glucose decrements from $88 \pm 3$ to $80 \pm 1 \mathrm{mg} / \mathrm{dl}$ (full circles) or during maintenance of euglycemia (glucose clamp technique, open circles) in six normal subjects. 
In the control study in which plasma glucose decrements were prevented by the euglycemic glucose clamp technique, plasma glucose concentration was maintained at $90 \pm 1 \mathrm{mg} / \mathrm{dl}$ $(P=$ NS vs fasting plasma glucose values of $89 \pm 3 \mathrm{mg} / \mathrm{dl}$, c.v. $2.9 \pm 0.1 \%$ ). In the study in which plasma glucose concentration was allowed to decrease by $8 \pm 1 \mathrm{mg} / \mathrm{dl}$ below fasting values $(88 \pm 3 \mathrm{mg} / \mathrm{dl})$ within $28 \pm 2 \mathrm{~min}$, plasma glucose concentration was maintained at $80 \pm 1 \mathrm{mg} / \mathrm{dl}$ for $150 \mathrm{~min}$ (c.v. $2.8 \pm 0.1 \%$ ) (Fig. 1). Finally, in the study in which plasma glucose concentration was allowed to decrease by $15 \pm 1 \mathrm{mg} / \mathrm{dl}$ below fasting values within $56 \pm 3$ min, plasma glucose concentration was maintained at $72 \pm 1 \mathrm{mg} / \mathrm{dl}$ for $120 \mathrm{~min}$ (c.v. $3.2 \pm 0.1 \%$ ) (Fig. 2).

The latency of the P300 wave and the plasma counterregulatory hormone concentration did not change either in the control study (euglycemia) or when plasma glucose concentration was allowed to decrease from $88 \pm 3$ to $80 \pm 1 \mathrm{mg} / \mathrm{dl}$ (Fig. 1). No subjects referred symptoms of hypoglycemia.

When plasma glucose concentration was decreased from $87 \pm 3$ to $72 \pm 1 \mathrm{mg} / \mathrm{dl}$ for $120 \mathrm{~min}$, the latency of the P300 wave increased from $301 \pm 12 \mathrm{~ms}$ to $348 \pm 20 \mathrm{~ms}$ at $60 \mathrm{~min}(P<0.01)$ and remained increased by approximately $22 \%$ throughout the

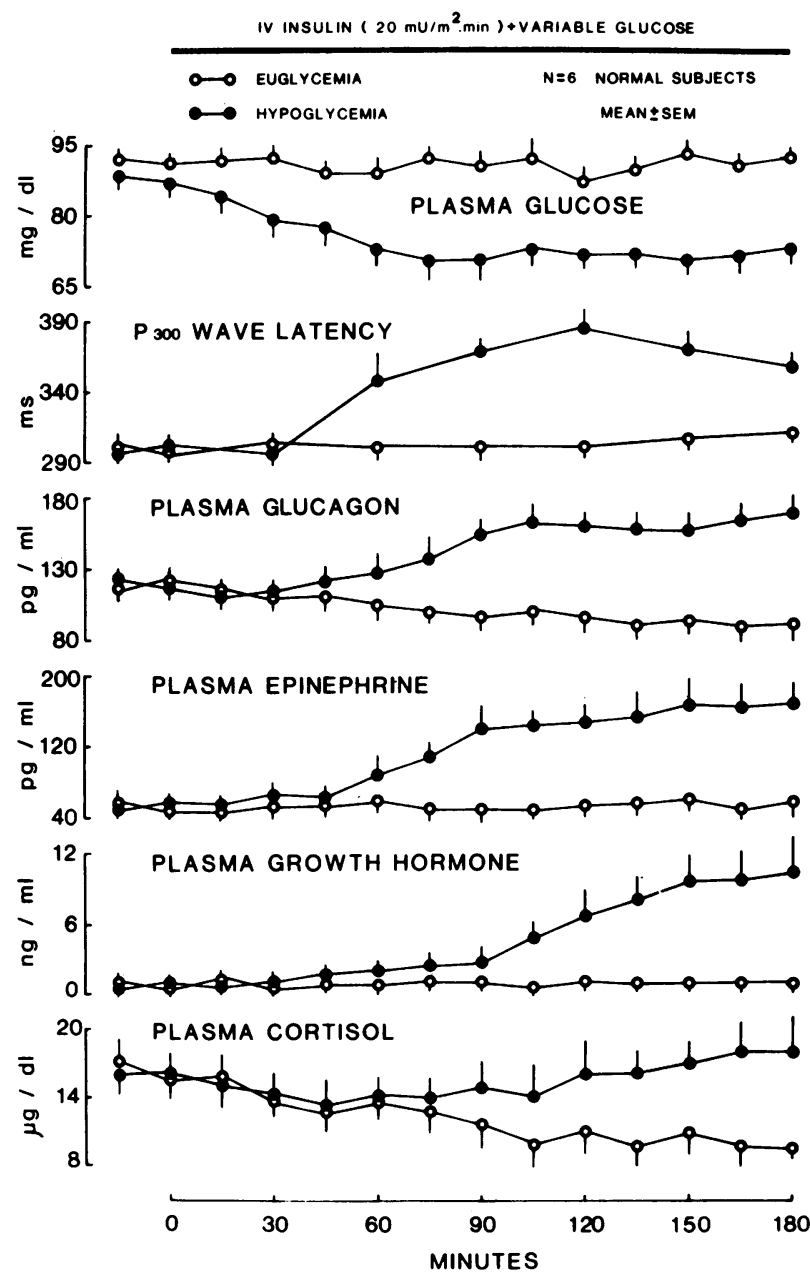

Figure 2. Cognitive function (latency of $\mathrm{P} 300$ wave), and plasma counterregulatory hormones in response to insulin-induced plasma glucose decrements from $87 \pm 3$ to $72 \pm 1 \mathrm{mg} / \mathrm{dl}$ (full circles) or during maintainance of euglycemia (glucose clamp technique, open circles) in six normal subjects. study. The plasma concentration of all counterregulatory hormones increased significantly in response to the plasma glucose decrement 30-45 min after the increase in latency of the P300 wave (Fig. 2). Plasma glucagon increased from $116 \pm 10$ to $153 \pm 16 \mathrm{pg} / \mathrm{ml}$ at $90 \mathrm{~min}(P<0.05)$ and remained increased at $162 \pm 10 \mathrm{pg} / \mathrm{ml}$ throughout the study. Plasma epinephrine increased from $54 \pm 9 \mathrm{pg} / \mathrm{ml}$ to $138 \pm 26 \mathrm{pg} / \mathrm{ml}(P<0.05)$ at 90 $\mathrm{min}$ and remained increased at $157 \pm 18 \mathrm{pg} / \mathrm{ml}$ throughout. Plasma growth hormone increased from $1.1 \pm 0.4$ to $4.9 \pm 1.5$ $\mathrm{ng} / \mathrm{ml}(P<0.05)$ at $105 \mathrm{~min}$ and continued to increase to a peak value of $10.5 \pm 3 \mathrm{ng} / \mathrm{ml}$ at $180 \mathrm{~min}$. Plasma cortisol was greater than in the control study from 150 to $180 \mathrm{~min}(17 \pm 2$ $\mu \mathrm{g} / \mathrm{dl}$ vs. $10 \pm 2 \mu \mathrm{g} / \mathrm{dl}, P<0.05$ ) (Fig. 2). The FFA and B-OH-B concentration decreased in response to hyperinsulinemia at 45 min in all the studies (Table I). However, in the studies in which plasma glucose concentration was either maintained at baseline or allowed to decrease at $80 \pm 1 \mathrm{mg} / \mathrm{dl}$, plasma FFA and $\mathrm{B}-\mathrm{OH}-\mathrm{B}$ concentration continued to decrease throughout and at 180 min they were suppressed by $\sim 40$ and 55 percent, respectively. In contrast, in the study in which plasma glucose concentration was allowed to decrease at $72 \pm 1 \mathrm{mg} / \mathrm{dl}$, plasma FFA and B-OH-B initially decreased to nadir values of $0.3 \pm 0.05 \mathrm{mM}$ at $75 \mathrm{~min}$ and $0.126 \pm 0.011 \mathrm{mM}$ at $90 \mathrm{~min}$, respectively, but subsequently increased despite hyperinsulinemia to values no longer different from baseline (FFA at 120 $\mathrm{min}, \mathrm{B}-\mathrm{OH}-\mathrm{B}$ at $150 \mathrm{~min}$ ) (Table I).

In the studies in which plasma glucose concentration was maintained either at $90 \pm 1$ and at $80 \pm 1 \mathrm{mg} / \mathrm{dl}$ and hormonal counterregulation was not activated, the amount of exogenous glucose required to maintain the target plasma glucose concentration increased continuously with time (peak at $180 \mathrm{~min}$, Table II), as previously reported $(23,24)$. On the contrary, in the study in which plasma glucose concentration was allowed to decrease at $72 \pm 1 \mathrm{mg} / \mathrm{dl}$ and hormonal counterregulation was activated, the glucose infusion rates decreased between 90 and $180 \mathrm{~min}$ from $0.9 \pm 0.3 \mathrm{mg} / \mathrm{kg} \cdot \mathrm{min}$ to $0.3 \pm 0.1$ $\mathrm{mg} / \mathrm{kg} \cdot \min (P<0.05)$. This suggests that the counterregulatory hormonal response was efficient in limiting the plasma glucose lowering effect of insulin. No subjects referred symptoms of hypoglycemia throughout the studies.

\section{Study $B$}

Effects of greater decrements in plasma glucose concentration and subsequent glucose recovery on brain function, hormonal counterregulation and symptoms of hypoglycemia. In these studies plasma insulin concentration increased from the baseline value of $11 \pm 1$ to $86 \pm 6 \mu \mathrm{U} / \mathrm{ml}$ between 45 and $75 \mathrm{~min}$ with no differences between the study in which plasma glucose concentration was maintained at baseline values or allowed to decrease. Following withdrawal of insulin infusion at $75 \mathrm{~min}$, plasma insulin concentration decreased rapidly and was no longer statistically different from the baseline values at 105 min in both studies (Figs. 3 and 4; Table III).

In the study in which the decrease in plasma glucose concentration was prevented (control study) the steady state plasma glucose concentration was $88 \pm 2 \mathrm{mg} / \mathrm{dl}(P=$ NS versus baseline $88 \pm 2 \mathrm{mg} / \mathrm{dl}$, c.v. $3.3 \pm 0.1 \%$ ). There were no changes in the latency of the P300 wave, nor in the plasma concentration of counterregulatory hormones. As expected, no subject referred symptoms of hypoglycemia.

In the studies in which plasma glucose was allowed to decrease, the step-wise plasma glucose decrements observed were 


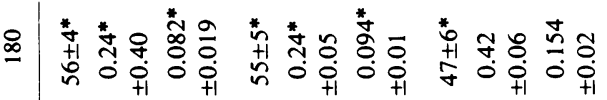

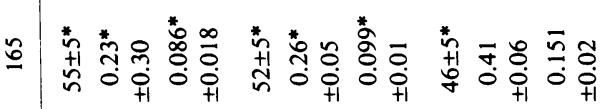

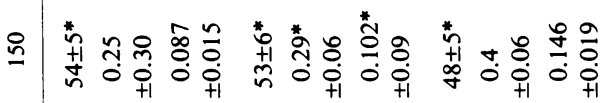

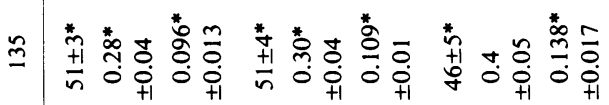

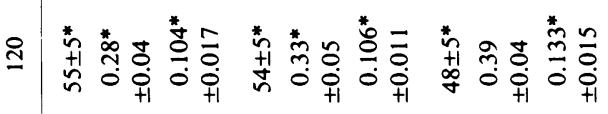

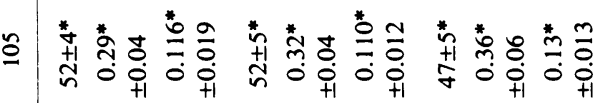

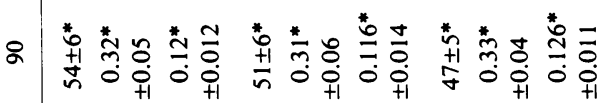

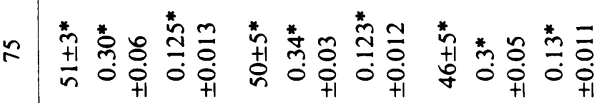

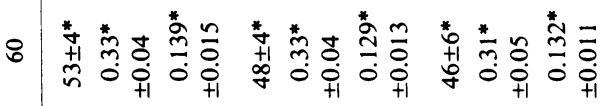

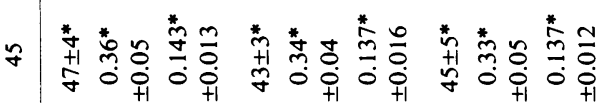

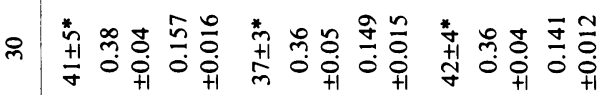

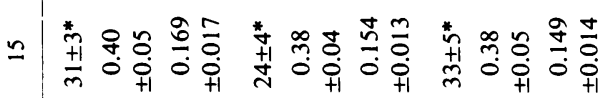

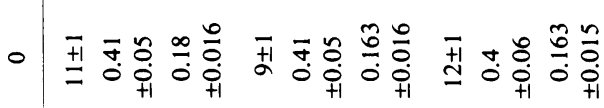

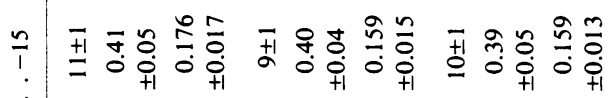
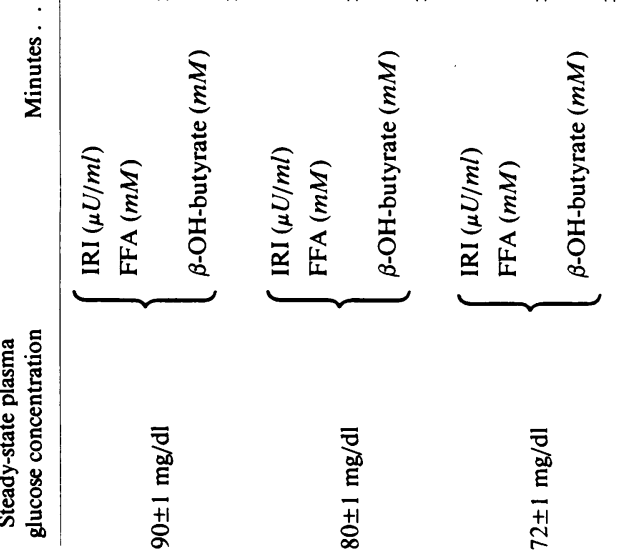

superimposable to those expected. Plasma glucose decreased from a baseline value of $85 \pm 2 \mathrm{mg} / \mathrm{dl}$ to plateau values $68 \pm 2$ $\mathrm{mg} / \mathrm{dl}$ between 20 and $25 \mathrm{~min}$; to $57 \pm 2 \mathrm{mg} / \mathrm{dl}$ between 35 and $40 \mathrm{~min}$; to $50 \pm 1 \mathrm{mg} / \mathrm{dl}$ between 45 and $75 \mathrm{~min}$. Thereafter, plasma glucose was allowed to increase to the normal fasting values (at $105 \mathrm{~min} 83 \pm 2 \mathrm{mg} / \mathrm{dl}, P=\mathrm{NS}$ versus baseline) and was maintained at euglycemic levels throughout the remaining part of the study. The latency of P300 wave increased significantly already at $20 \mathrm{~min}$ from $296 \pm 9$ to $347 \pm 26 \mathrm{~ms}(P<0.05$ versus control study) and increased further when plasma glucose concentration continued to decrease between 45 and 75 $\min (370 \pm 26 \mathrm{~ms}, P<0.01)$. When plasma glucose concentration was normalized at $105 \mathrm{~min}$, the latency of $\mathrm{P} 300$ wave was still greater than in the control study $(339 \pm 15$ vs. $298 \pm 10 \mathrm{~ms}$, $P<0.05$ ). Only after 30 additional min of euglycemia the latency of P300 wave was normalized $(317 \pm 13 \mathrm{~ms})$ as compared both to baseline values $(296 \pm 9 \mathrm{~ms})$ and to the control study $(309 \pm 12 \mathrm{~ms})(P=\mathrm{NS})$. There was a significant (inverse) correlation between plasma glucose concentration and the corresponding latency of P300 wave $(r=-0.76, P<0.001)$ (Fig. 4). All counterregulatory hormones increased in response to the plasma glucose decreases. Both plasma glucagon and epinephrine increased at $35 \mathrm{~min}$ (glucagon from $89 \pm 9$ to $147 \pm 15 \mathrm{pg} / \mathrm{ml}$, epinephrine from $42 \pm 12$ to $157 \pm 29 \mathrm{pg} / \mathrm{ml}$, both $P<0.05)$, both peaked at $75 \mathrm{~min}(215 \pm 18$ and $389 \pm 46$ $\mathrm{pg} / \mathrm{ml}$, respectively) and both remained increased until $90 \mathrm{~min}$ $(P<0.05)$. Plasma growth hormone increased significantly at $45 \min (13 \pm 3.5$ vs. $0.7 \pm 0.2 \mathrm{ng} / \mathrm{ml}, P<0.05)$, peaked at 75 $\min (26 \pm 5.3 \mathrm{pg} / \mathrm{ml})$ and remained increased until $90 \mathrm{~min}$ $(20 \pm 3.9 \mathrm{ng} / \mathrm{ml}$ vs. $2.2 \pm 0.5 \mathrm{pg} / \mathrm{ml}$ of the control study, $P$ $<0.05)$. Plasma cortisol increased at $60 \mathrm{~min}(23 \pm 4$ vs. $15 \pm 2$ $\mu \mathrm{g} / \mathrm{dl}, P<0.05)$, peaked at $75 \mathrm{~min}(26 \pm 4 \mu \mathrm{g} / \mathrm{dl})$ and was increased until $105 \mathrm{~min}(18 \pm 3$ vs. $12 \pm 2 \mu \mathrm{g} / \mathrm{dl}$ of the control study $(P<0.05)$.

The plasma concentration of FFA and B-OH-B was initially suppressed to a similar extent both in the control study and in the study in which plasma glucose concentration was allowed to decrease until $60 \mathrm{~min}$ (Table III). Following withdrawal of insulin infusion, plasma FFA and B-OH-B concentration increased in both studies. However, in the study in which plasma glucose concentration was allowed to decrease, plasma FFA and B-OH-B concentration increased at $135 \mathrm{~min}$ approximately by 100 and $65 \%$, respectively, as compared to baseline. In contrast, in the control study FFA and B-OH-B concentration just approached the baseline values.

In the study in which plasma glucose was allowed to decrease the patients referred both adrenergic and neuroglycopenic symptoms at $45 \mathrm{~min}$ when plasma glucose concentration was $49 \pm 2 \mathrm{mg} / \mathrm{dl}$. The score peak of both adrenergic and neuroglycopenic symptoms occurred at $75 \mathrm{~min}$ at the end of the plateau plasma glucose concentration of $50 \mathrm{mg} / \mathrm{dl}$. Following normalization of plasma glucose, the hypoglycemia symptoms were no longer different from those of the control study (neuroglycopenic symptoms at $90 \mathrm{~min}$; adrenergic symptoms at $105 \mathrm{~min})$.

\section{Discussion}

The present study shows that acute, modest decrements in plasma glucose concentration $(\sim 15 \mathrm{mg} / \mathrm{dl}$ below the postabsorptive values) result in an early impairment in brain function, followed by activation of hormonal glucose counterregu- 
Table II. Glucose Infusion Rates Required to Maintain Plasma Glucose Concentration at Three Different Steady-state Levels during Intravenous Insulin Infusion $\left(20 \mathrm{mU} / \mathrm{m}^{2} \cdot \min\right.$ for $180 \mathrm{~min}$ ) in Six Normal Subjects (Study A)

\begin{tabular}{cccccccc}
\hline $\begin{array}{c}\text { Steady-state plasma } \\
\text { glucose concentration }\end{array}$ & Minutes . . 0 & 30 & 60 & 90 & 120 & 150 \\
\hline$m g / d l$ & & & Glucose infusion rates $(\mathrm{mg} / \mathrm{kg} \cdot \min )$ \\
$90 \pm 1$ & 0 & $1.5 \pm 0.2$ & $3.8 \pm 0.4$ & $4.5 \pm 0.4$ & $4.7 \pm 0.4$ & $5.1 \pm 0.5$ \\
$80 \pm 1$ & 0 & $0.1 \pm 0.1$ & $2.5 \pm 0.4$ & $3.1 \pm 0.4$ & $3.3 \pm 0.5$ & $3.7 \pm 0.4$ & $4.6 \pm 0.4$ \\
$72 \pm 1$ & 0 & 0 & $0.5 \pm 0.1$ & $0.9 \pm 0.3$ & $0.7 \pm 0.2^{*}$ & $0.5 \pm 0.1^{*}$ & $0.3 \pm 0.1^{*}$ \\
\hline
\end{tabular}

* $P<0.05$ versus the peak value at $90 \mathrm{~min}$.

lation, in the absence of symptoms of hypoglycemia. More profound decrements in plasma glucose $(\sim 35 \mathrm{mg} / \mathrm{dl}$ below the postabsorptive values) further impair brain function, exaggerate hormonal counterregulation and finally result in symptoms of hypoglycemia. Thus, it appears that the glycemic threshold for the onset of neuroglycopenia is greater than currently appreciated $(3-8,25,26)$, and that, although the absolute glycemic threshold for onset of neuroglycopenia and activation of hormonal counterregulation is virtually identical, the onset of the latter follows that of the former.

The major finding of the present study, i.e., the exquisite sensitivity of the brain to minor decreases in ambient plasma glucose, relies entirely on the assumption that impairment in cognitive function as measured by means of the latency of the P300 wave, closely reflects impaired brain glucose metabolism, i.e., neuroglycopenia.

The P300 wave is the most prominent component of event-related potentials $(19,20)$ and reflects the active cognitive processing of the stimulus information by the subject (27). The generation of the $\mathrm{P} 300$ wave implies both perception and cognition of task relevant stimuli (acoustic, somatosensorial and visual) and its latency expresses the time required for the complete evaluation of the stimulus (28). Several studies suggest that the latency of $\mathrm{P} 300$ wave is involved in the process of

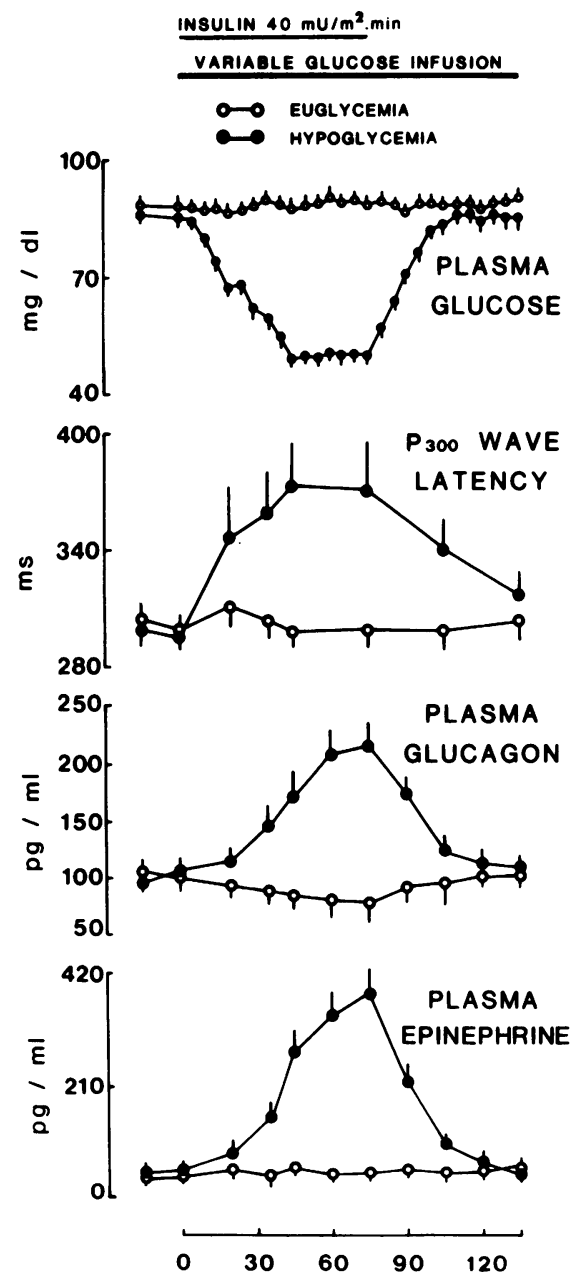

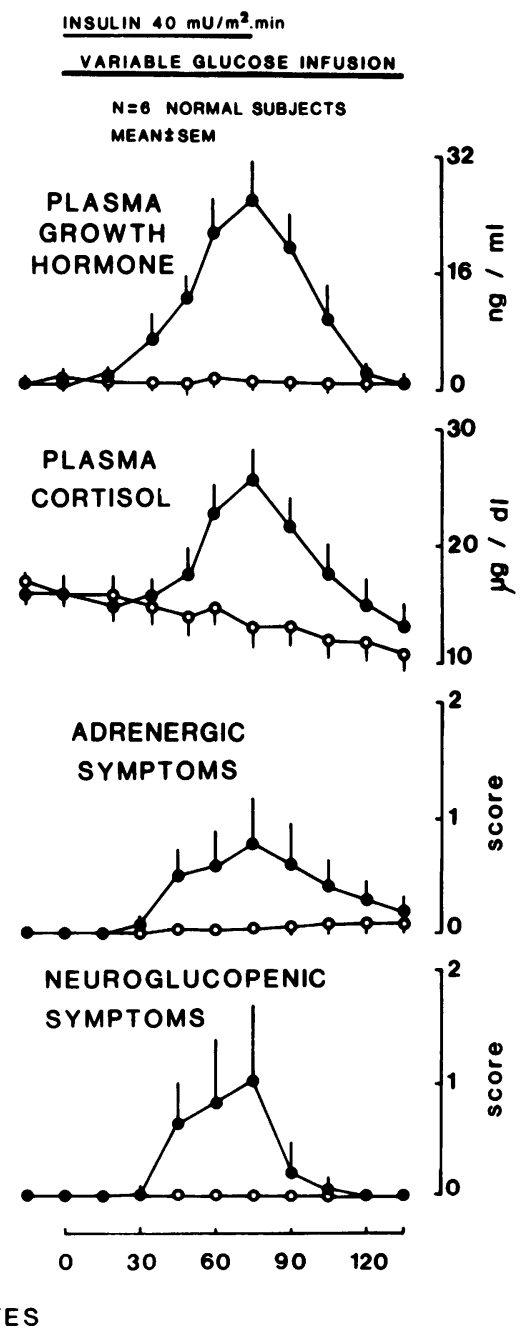

Figure 3. Cognitive function (latency of $\mathrm{P} 300$ wave), plasma $C R$ hormones and score of hypoglycemic symptoms in response to insulin-induced, glucose-controlled hypoglycemia and subsequent recovery of plasma glucose (full circles), or during maintenance of euglycemia (glucose clamp technique, open circles) in six normal subjects. 


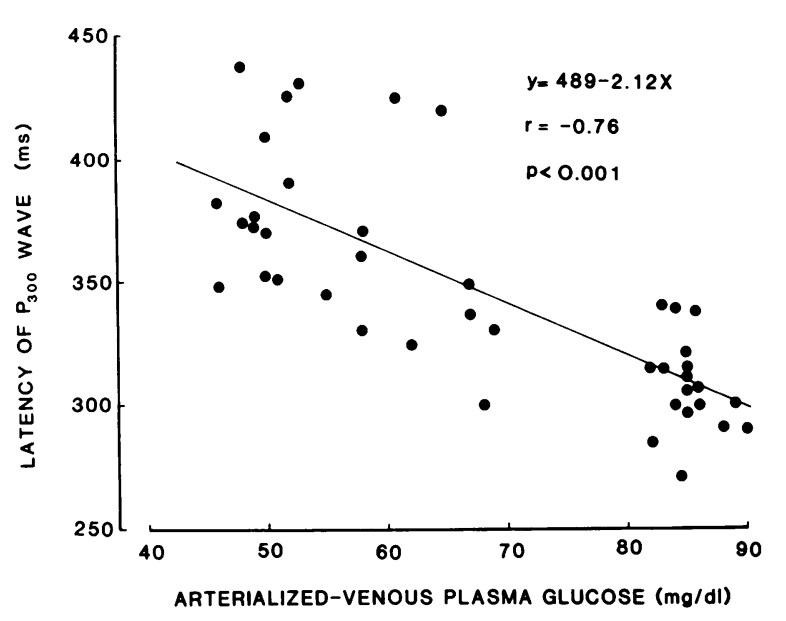

Figure 4. Correlation between plasma glucose concentration and cognitive function (latency of the P300 wave) in the experiments of Fig. 3 (insulin-induced, glucose controlled hypoglycemia and subsequent recovery of plasma glucose).

storing information, i.e., memory, as indicated by the observation that the origin of the P300 wave is from the medial temporal lobe areas $(29,30)$ that the latency of the P300 wave increases with the increasing memory load (31) and that it is closely related to the memory digit span test (32). In addition, since aging (33), dementia (20), Huntington's disease (34) and organic cognitive disorders in children (21) are associated with an increased latency in P300 wave, it is concluded that the latency of the P300 wave not only is related to some of the most important brain cortical functions in man, but also that such a parameter might be used as a measure of physiological integrity of cognitive function.

In the present studies the latency of the P300 wave evoked by acoustic stimuli was found to be highly reproducible in the same subjects tested several times in euglycemic conditions. Consequently, the fact that the latency of the P300 wave increased in a proportional mode to the magnitude of the plasma glucose decrements (Fig. 4), strongly supports the concept that the changes in the latency of P300 observed in this study were specifically caused by, and not simply associated with, the correspondent changes in plasma glucose concentration. Thus, the assumption that the latency of $\mathrm{P} 300$ wave is a specific and sensitive measure of cortical cognitive function, which is in turn influenced by brain metabolism, is validated.

It should be pointed out that the glycemic threshold for onset of neuroglycopenia found in this study $(\sim 72 \mathrm{mg} / \mathrm{dl}$, arterialized-venous plasma) applies to conditions of short-term fasting of normal individuals in whom acute decreases in arterial plasma glucose concentration were induced. Clearly, further studies are needed to establish the glycemic threshold for onset of neuroglycopenia under different experimental conditions, such as for example prolonged fasting state in normal subjects, which result in a plasma glucose decrease $>15 \mathrm{mg} / \mathrm{dl}$ below the postabsorptive values (35), or diabetes mellitus. In addition, the threshold for onset of neuroglycopenia in the present studies was based on measurement of arterialized venous plasma glucose during combined insulin and glucose infusion. Since under these experimental conditions there is a substantial arteriovenous gradient in plasma glucose concentration (9), the glycemic threshold for neuroglycopenia would be lower if venous rather than arterialized-venous blood were drawn for plasma glucose measurement.

Theoretically, the changes in plasma concentration of counterregulatory hormones and substrates other than glucose, which occurred during the hypoglycemic clamp studies rather than the changes in plasma glucose concentration itself might have been responsible for, or at least contributed to the increased latency of the P300 wave. However it is unlikely that this was the case in our study. First, the increased latency of the P300 wave did actually precede and not followed the response of counterregulatory hormones (Figs. 2 and 3). Second, although theoretically the brain can oxidize ketones, and the plasma B-OH-B concentration decreased at the same time at which the latency of the P300 wave increased during insulininduced hypoglycemia, there was no increase in the latency of the $\mathrm{P} 300$ wave in the experiment in which the plasma B-OH-B was decreased to a much greater extent, but decreases in plasma glucose concentration from baseline were prevented (hyperinsulinemic-euglycemic clamp, Figs. 2 and 3, Tables I and III). Finally, although lactate may be potentially oxidized by the brain (36) and changes in its plasma concentration might affect cerebral function, it is unlikely that this substrate contributed to the onset of the increased latency of the P300 wave, because plasma lactate concentration does not change in an early phase of hypoglycemia, but increases only in the recovery phase (37).

Previous studies which have examined brain function by means of neuropsychological tests (3-5), visual reaction time (6), and electroencephalography $(7,8)$ have not reported abnormalities for minor asymptomatic plasma glucose decrements. It is likely that the different plasma glucose threshold for neuroglycopenia found in those studies $(\sim 50-55 \mathrm{mg} / \mathrm{dl})$ and in the present study ( $\sim 72 \mathrm{mg} / \mathrm{dl})$ may be explained by the different methodological approach used to investigate brain function. In fact, the latency of the P300 wave appears as a much more sensitive index of brain cortical function and onset of neuroglycopenia as compared to the methods used in those studies.

Under normal conditions, the activity of the enzyme hexokinase and not the glucose carrier transport system through the blood-brain barrier is the rate limiting step for glucose oxidation by the brain (36). Previous studies in rats have shown that only for a $50 \%$ decrease in plasma glucose concentration, the glucose substrate availability becomes the rate limiting step for glycolysis in the brain (2). The present study in which only a $16 \%$ decrease in postabsorptive plasma glucose concentration impaired cortical brain function as a result of impaired oxidative metabolism, indirectly suggests that the brain becomes substrate dependent for glucose oxidation at a glycemic threshold greater than currently thought $(3-8,38)$. Thus, prevention of even modest decreases in plasma glucose concentration in man is critical for maintenance of normal brain metabolism and function.

The findings of the present studies, i.e., that a minor decrease in plasma glucose concentration already impairs cortical function, are potentially relevant to the definition of the safety of the glycemic threshold in diabetic patients treated either with insulin and/or oral hypoglycemic agents. According to findings of the present study, a conservative criteria to prevent neuroglycopenia in treated diabetic patients would be prevention of fall of plasma glucose concentration below the postabsorptive values of nondiabetic individuals. However, 
the extent to which brain metabolism in diabetics is similar to that of normal subjects is presently unknown. Since the antecedent glycemic level influences brain glucose transport, i.e., chronic hyperglycemia reduces $(39,40)$ and chronic hypoglycemia increases (41) glucose transport to the brain, the results of the present study in normal nondiabetic subjects do not necessarily establish the glycemic threshold for onset of neuroglycopenia, activation of counterregulatory hormones and symptoms of hypoglycemia in diabetic patients. Actually, it has been shown that the glycemic threshold for activation of counterregulation and symptoms of hypoglycemia is increased in diabetic subjects chronically hyperglycemic (42), whereas it is decreased in diabetics treated with regimens of intensive insulin therapy (42-47) which result in chronically subnormal plasma glucose concentrations (48). Nevertheless, the present study suggests that any therapeutic regimen which causes even modest decreases in plasma glucose concentration below the postabsorptive values of nondiabetic subjects might be potentially dangerous for brain function of diabetic subjects.

The definition of glycemic threshold for activation of counterregulatory hormones deserves comment. When in the present studies the glycemic threshold for hormonal counterregulation was evaluated in the step-wise plasma glucose decrement protocol (study B) in which a given plateau plasma glucose concentration was maintained for several minutes, plasma glucagon and epinephrine increased at plasma glucose concentration of $\sim 60 \mathrm{mg} / \mathrm{dl}$, and growth hormone and cortisol at $\sim 50 \mathrm{mg} / \mathrm{dl}$. However, when the glycemic threshold for activation of hormonal counterregulation was evaluated in the protocol of single-step decrease in plasma glucose, which was held for at least 120 min (study A), the glycemic threshold was found to be greater ( $72 \mathrm{mg} / \mathrm{dl})$ and, most important, it was identical for all counterregulatory hormones. Thus, it appears that the duration of plasma glucose decrements and not only the absolute plasma glucose concentration is an important factor in inducing the responses of counterregulatory hormones. It is likely that such a factor accounts for the differences in glycemic thresholds for increased plasma cortisol between this study $(72 \pm 1 \mathrm{mg} / \mathrm{dl})$ and that of Schwartz et al. $(58 \pm 3 \mathrm{mg} / \mathrm{dl})(26)$. In the present study the glycemic threshold was calculated as the plasma glucose concentration at which P300 wave latency and counterregulatory hormones significantly increased or hypoglycemic symptoms were recorded as compared to the control study. In the study of Schwartz et al. thresholds were calculated at the glucose values during the plasma glucose reduction at which a given parameter exceeded the $95 \%$ confidence interval from the euglycemic studies. Noneless, the threshold estimated for symptoms of hypoglycemia in the protocol of rapid step-wise decrease in plasma glucose concentration $(49 \pm 2 \mathrm{mg} / \mathrm{dl})$ are remarkably similar and confirmatory of Schwartz et al. (53 $\pm 2 \mathrm{mg} / \mathrm{dl})(26)$.

In the present study the glycemic threshold for adrenergic and neuroglycopenic symptoms was identical. Thus, the observation that significant neuroglycopenia developed and hormonal counterregulation was activated in the absence of symptoms of hypoglycemia, reinforce the concept that the "hypoglycemic symptoms" are a late indicator of plasma glucose decrements below normal values, as recently reported by Schwartz et al. (26).

The relationship found in this study between plasma glucose concentration, brain function and activation of counterregulatory hormones is relevant to the definition of hypoglyce-

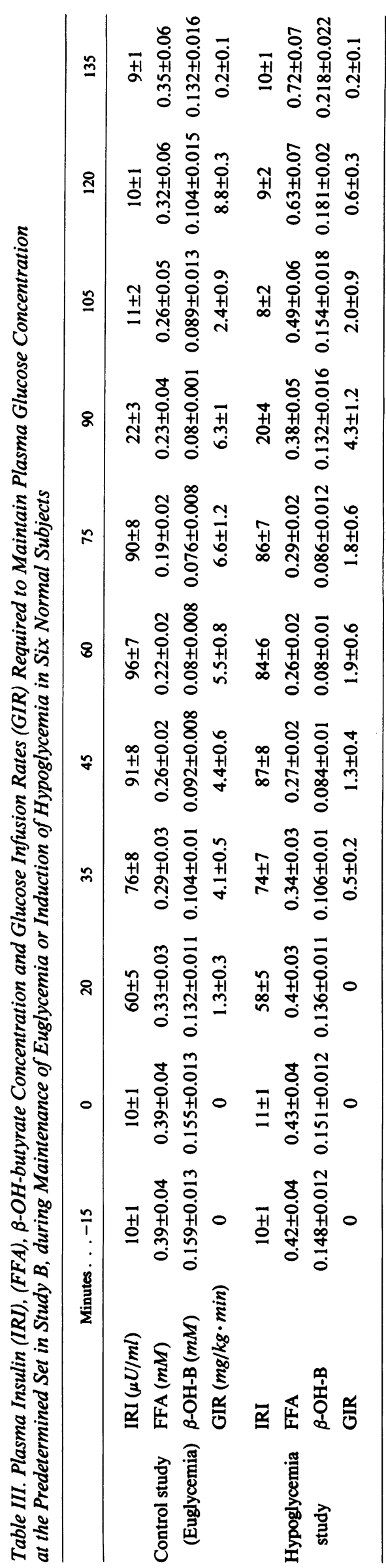


mia. At present, hypoglycemia is defined as a plasma glucose concentration at which symptoms and signs of brain dysfunction appear, i.e., $55-50 \mathrm{mg} / \mathrm{dl}$ (3-7). In contrast, the present study shows for the first time in man that the glycemic threshold for acute neuroglycopenia is $\sim 15 \mathrm{mg} / \mathrm{dl}$ below the postabsorptive values. Consequently, since the most relevant metabolic consequence of decreased plasma glucose concentration is neuroglycopenia, the term hypoglycemia should be used to indicate the glycemic threshold for onset of neuroglycopenia, i.e., $70-75 \mathrm{mg} / \mathrm{dl}$ after a short-term fast (postabsorptive state) in normal mán.

In previous studies, the glycemic threshold for hormonal counterregulation $(26,35,49)$ has been found to be greater $(\sim 70 \mathrm{mg} / \mathrm{dl})$ than that of neuroglycopenia $(\sim 55-60 \mathrm{mg} / \mathrm{dl})$ investigated by means of neuropsychological tests (3-5), visual reaction time (6), and electroencephalography $(7,8)$. In the present study in which a more sensitive approach to evaluate brain function was used the activation of hormonal counterregulation followed rather than preceded the onset of neuroglycopenia, although the absolute glycemic threshold for onset of neuroglycopenia and activation of counterregulation is virtually identical. Thus, this is the first physiological demonstration of the long-term thought, but never proven hypothesis that activation of counterregulatory responses of epinephrine, growth hormone and cortisol to hypoglycemia follows the onset of neuroglycopenia in man. Nevertheless, it should be noted that the absolute glycemic threshold for onset of neuroglycopenia and activation of counterregulation was identical and that it is likely that the time interval elapsing between increased latency of the $\mathrm{P} 300$ wave and the increase in plasma epinephrine (30 min, Fig. 2) might have been overestimated because of the higher sensitivity of the technique used to detect neuroglycopenia (negligible interval of the stimulus response for P300 wave latency) as compared to detection of increased epinephrine in plasma (which involves neural signaling and increase in hormone release sufficient to increase the plasma concentration).

In conclusion, the present study demonstrates that the glycemic threshold for onset of neuroglycopenia in normal man is much greater than currently appreciated, and that the counterregulatory hormones increase in plasma only after the onset of neuroglycopenia to prevent more severe brain dysfunction. Further studies are needed to investigate the glycemic threshold for neuroglycopenia in diabetic patients and its relationship with threshold for activated hormonal counterregulation and symptoms of hypoglycemia. However, until this information is not available, great care should be taken in diabetic patients treated with regimens of intensive insulin therapy to prevent decreases in plasma glucose concentration potentially below the glycemic threshold for neuroglycopenia.

\section{Acknowledgments}

This work was supported by the Consiglio Nazionale delle Ricerche (C.N.R.) finalized project "Complications of Diabetes." Ob. 46, and C.N.R. grant 86.00021.04.

\section{References}

1. Cryer, P. E., and J. E. Gerich. 1985. Glucose counterregulation, hypoglycemia and intensive insulin therapy in diabetes mellitus. $N$. Engl. J. Med. 313:232-241.
2. Robinson, P. J., and S. I. Rapoport. 1986. Glucose transport and metabolism in the brain. Am. J. Physiol. 250:R127-R136.

3. Holmes, C. S., J. T. Hayford, J. L. Gonzales, and Y. A. Weydert. 1983. A survey of cognitive functioning at different glucose levels in diabetic persons. Diabetes Care. 6:180-185.

4. Holmes, C. S., K. M. Koepke, R. G. Thompson, P. W. Gyves, and Y. A. Weydert. 1984. Verbal fluency and naming performances in type 1 diabetes at different blood glucose concentrations. Diabetes Care. 7:454-459.

5. Pramming, S., B. Thorsteinsson, A. Theilgaard, E. M. Pinner, and C. Binder. 1986. Cognitive function during hypoglycaemia in type 1 diabetes mellitus. Br. Med. J. 292:647-650.

6. Herold, K. C., K. S. Polonsky, R. M. Cohen, J. Levy, and F. Douglas. 1985. Variable deterioration in cortical function during insulin-induced hypoglycemia. Diabetes. 34:677-685.

7. Pramming, S., B. Thorsteinsson, B. Stigsby, C. Binder. 1988. Glycaemic threshold for changes in electroencephalograms during hypoglycaemia in patients with insulin-dependent diabetes. Br. Med. J. 296:665-667.

8. Tamburrano, G., A. Lala, F. Leonetti, N. Locuratolo, and S. Busco. 1987. Electroencefalography during prolonged hypoglycemia. In Hypoglycemia. D. Andreani, V. Marks, and P. J. Lefebvre, editors. Raven Press, New York. 181-194.

9. McGuire, E., J. Helderman, R. Tobin, R. Andres, and M. Berman. 1976. Effects of arterial versus venous sampling on analysis of glucose kinetics in man. J. Appl. Physiol. 41:565-573.

10. De Fronzo, R. A., J. D. Tobin, and R. Andres. 1979. Glucose clamp technique: a method for quantifying insulin secretion and resistance. Am. J. Physiol. 237:E214-E223.

11. Bolli, G., P. De Feo, G. Perriello, S. De Cosmo, P. Compagnucci, F. Santeusanio, P. Brunetti and R. H. Unger. 1984. Mechanisms of glucagon secretion during insulin-induced hypoglycemia in man. $J$. Clin. Invest. 73:917-922.

12. Hebert, V., K. Lau, C. Gottlieb, and S. Bleicher. 1965. Coated charcoal immunoassay of insulin. J. Clin. Endocrinol. Metab. 25:1375-1384.

13. Faloona, G., and R. H. Unger. 1974. Glucagon. In Methods of Hormone Radioimmunoassay. B. Jaffe and H. Behrman, editors. Academic Press, Inc., New York. 317-330.

14. Da Prada, M., and G. Zurcher. 1976. Simultaneous radioenzymatic determination of plasma and tissue adrenaline, noradrenaline and dopamine within the femtomole range. Life Sci. 19:1161-1174.

15. Mattingly, D. 1964. A simple fluorimetric method for the estimation of 11-hydroxycorticoids in human plasma. J. Clin. Pathol. 15:374-379.

16. Peake, G. 1972. Growth Hormone. In Methods of Hormone Radioimmunoassay. B. Jaffe and H. Berhman, editors. Academic Press, Inc., New York. 103-121.

17. Dole, V., and H. Meinertz. 1960. Microdetermination of longchain fatty acids in plasma and tissues. J. Biol. Chem. 235:2595-2599.

18. Lowry, O., and J. Passoneau. 1972. Typical fluorimetric procedures for metabolic assays. In Flexible System for Enzymatic Analysis. O. Lowry and J. Passoneau, editors. Academic Press, Inc., New York. 89-92.

19. Sutton, S., M. Braren, M. Zubin, and E. R. John. 1965. Evoked potential correlates of stimulus uncertainty. Science (Wash. DC). 150:1187-1188.

20. Goodin, D. S., K. C. Squires, and A. Starr. 1978. Long latency event-related components of the auditory evoked potential in dementia. Brain. 101:635-648.

21. Finley, W. W., S. F. Faux, J. H. Hutcheson, and L. Amstutz. 1985. Long-latency event-related potentials in the evaluation of cognitive function in children. Neurology. 35:323-327.

22. Zar, J. 1984. Biostatistical Analysis. Prentice Hall, Englewood Cliffs, NJ.

23. Doberne, L., M. S. Greenfield, B. Schultz, and G. M. Reaven. 1981. Enhanced glucose utilization during prolonged clamp studies. Diabetes. 30:829-835. 
24. De Feo, P., G. B. Bolli, M. M. Ventura, G. Perriello, S. De Cosmo, F. Santeusanio, and P. Brunetti. 1984. Rapid variations in glucose uptake in vivo: evidence for a circadian rhythm in insulin action in man. Diabetologia. 27:268a. (Abstr.)

25. Marks, V. and F. C. Rose. 1981. Hypoglycaemia. Blackwell Scientific Publications, Oxford. 1-521.

26. Schwartz, N. S., W. E. Clutter, S. D. Shah, and P. E. Cryer. 1987. Glycemic thresholds for activation of glucose counterregulatory systems are higher than the threshold for symptoms. J. Clin. Invest. 79:777-781.

27. Hillyard, S. A., and M. Kutas. 1983. Electrophysiology of cognitive processing. Annu. Rev. Psycol. 34:33-61.

28. Pritchard, W. S. 1981. Psychophysiology of P300. Psychological Bull. 89:506-540.

29. Halgren, E., N. Squires, C. Wilson, J. Rohrbaugh, T. Bab, and P. Crandall. 1980. Endogenous potentials generated in the human hippocampal formation and amygdala by infrequent events. Science (Wash. DC). 210:803-805.

30. Okada, Y. C., L. Kaufman, and S. J. Williamson. 1983. The hippocampal formation as a source of the slow endogenous potentials. Electroencephalogr. Clin. Neurophysiol. 55:417-426.

31. Adam, N., and G. I. Collins. 1978. Late components of the visual evoked potential to search in short-term memory. Electroencephalogr. Clin. Neurophysiol. 44:147-156.

32. Polich, J., L. Howard, and A. Starr. 1983. P300 latency correlates with digit span. Psychophysiology. 20:665-669.

33. Goodin, D., K. Squires, B. Henderson, and A. Starr. 1978. Age-related variations in evoked potentials to auditory stimuli in normal human subjects. Electroenphalogr. Clin. Neurophysiol. 44:447458.

34. Rosenberg, C., K. Nudleman, and A. Starr. 1985. Cognitive evoked potentials (P300) in early Huntington's disease. Arch. Neurol. 42:984-987.

35. Bolli, G., I. Gottesman, P. Cryer, and J. Gerich. 1984. Glucose counterregulation during prolonged hypoglycemia in normal man. Am. J. Physiol. 247:E206-E214.

36. Pardrige, W. M. 1983. Brain metabolism: a perspective from the blood-brain barrier. Physiol. Rev. 63:1481-1535.

37. Corral, R. J. M., B. M. Frier, N McD. Davidson and E. B. French. 1981. Hormonal and substrate responses during recovery from hypoglycaemia in man during betal-selective and non-selective betaadrenergic blockade. Eur. J. Clin. Invest. 11:279-283.

38. Bachelard, H. 1981. Cerebral metabolism and hypoglycaemia.
In Hypoglycaemia. V. Marks and F. C. Rose, editors. Blackwell Scientific Publications, Oxford. 51-68.

39. Gjedde, A., and C. Crone. 1981. Blood-brain glucose transfer: repression in chronic hyperglycemia. Science 214:456-457.

40. McCall, A. L., W. Millington, and R. J. Wurtman. 1982. Metabolic fuel and amino acid transport across the blood-brain barrier in experimental diabetes mellitus. Proc. Natl. Acad. Sci. USA. 79:54065410.

41. McCall, A. L., L. B. Fixman, N. Fleming, K. Tornheim, W. Chick, and N. B. Ruderman. 1986. Chronic hypoglycemia increases brain glucose transport. Am. J. Physiol. 251:E442-E447.

42. Boyle, P. J., N. S. Schwartz, S. D. Shah, W. E. Clutter, and P. E. Cryer. 1987. Glycemic thresholds for hypoglycemic symptoms are elevated in patients with poorly controlled insulin-dependent diabetes mellitus. Diabetes. 36:3A (Abstr.).

43. Bergenstal, R. M., K. S. Polonsky, G. Pons, J. B. Jaspan, A. H. Rubenstein. 1983. Lack of glucagon response to hypoglycemia in type 1 diabetics after long-term optimal therapy with a continuous subcutaneous insulin infusion pump. Diabetes. 32:398-402.

44. Arias, P., W. Kerner, H. Zier, I. Navascues, E. F. Pfeiffer. 1985. Incidence of hypoglycemic episodes in diabetic patients under continuous subcutaneous insulin infusion and intensified conventional treatment: assessment by means of semiambulatory 24-hour continuous blood glucose monitoring. Diabetes Care. 8:134-140.

45. Lager, I., S. Attvall, G. Blohmé, and U. Smith. 1986. Altered recognition of hypoglycaemic symptoms in type 1 diabetes during intensified control with continuous subcutaneous insulin infusion. $D i$ abetic Med. 3:322-325.

46. Simonson, D. C., W. V. Tamborlane, R. A. DeFronzo, and R. S. Sherwin. 1985. Intensive insulin therapy reduces counterregulatory hormone responses to hypoglycemia in patients with type 1 diabetes. Ann. Intern. Med. 103:184-190.

47. Amiel, S. A., W. V. Tamborlane, D. C. Simonson, and R. S. Sherwin. 1987. Defective counterregulation after strict glycemic control of insulin-dependent diabetes mellitus. N. Engl. J. Med. 316:1376-1383.

48. The DCCT Research Group. 1987. Diabetes control and complications trial (DCCT): results of feasibility study. Diabetes Care. 10:1-19.

49. De Feo, P., G. Perriello, S. De Cosmo, M. M. Ventura, P. J. Campbell, P. Brunetti, J. E. Gerich, and G. B. Bolli. 1986. Comparison of glucose counterregulation during short-term and prolonged hypoglycemia in normal humans. Diabetes. 35:563-569. 